\title{
DNA Island Formation on Binary Block Copolymer Vesicles
}

Qingjie Luo, ${ }^{\dagger}$ Zheng Shi, ${ }^{\dagger}$ Yitao Zhang,,$^{\dagger}$ Xi-Jun Chen,${ }^{\dagger}$ Seo-Yeon Han,${ }^{\dagger}$ Tobias Baumgart,${ }^{\dagger}$ David M. Chenoweth, ${ }^{\dagger}$ and So-Jung Park ${ }^{*}+,+$,

${ }^{\dagger}$ Department of Chemistry, University of Pennsylvania, 231 South 34th Street, Philadelphia, Pennsylvania 19104, United States

†Department of Chemistry and Nano Science, Ewha Womans University, Ewhayeodae-gil, Seodaemun-gu, Seoul 120-750, Korea

*Address correspondence to sojungpark@ewha.ac.kr. 
Materials. Tetrahydrofuran (THF) was purified by distillation over Na/benzophenone under argon. Other common solvents such as acetone, methanol, isopropanol, chloroform, and dichloromethane were used as received. 1,3-butadiene (BD) was purchased from Aldrich and purified by distillation over calcium hydride. Ethylene oxide (EO) purchased from Pfaltz\&Bauer was dried over calcium hydride and by distillation prior to use. sec-Butyllithium was purchased from Aldrich and used as received. The concentration of butyllithium was determined by diphenylacetic acid titration. Potassium naphthalenide solution was prepared by adding freshly cut potassium metal to a stirring naphthalene solution (THF) under nitrogen flow. The dark green solution was allowed to stir at room temperature for at least $2 \mathrm{~h}$ before use. Methyl acrylate was purchased from Sigma and purified through an alumina neutral column to remove inhibitors. The initiator (4,4'-azobis(4-cyanovaleric acid) (V-501)), $\quad$ RAFT agent (4-cyano-4-[(dodecylsulfanylthiocarbonyl)sulfanyl] pentanoic acid (RAFT-2.0)), $\mathrm{N}, \mathrm{N}$-diisopropylethylamine $\quad$ and 1-[Bis(dimethylamino)methylene]-1H-1,2,3-triazolo[4,5-b]pyridinium 3-oxid hexafluorophosphate (HATU) were purchased from Sigma and used as received. $\mathrm{PBD}_{46}-b-\mathrm{PEO}_{30}$ and $\mathrm{PS}_{48}-b-\mathrm{PEO}_{45}$ were purchased from Polymer Sources (Montreal, Canada). Oligonucleotides (DNA 1: 5'-A10-ATCCTTATCAATATT-FAM-3'; DNA 1': 5'-AATATTGATAAGGAT-T10-3'; DNA 2: 5'-ATCCTTATCAATATT-FAM-3'; DNA 2': 5'-A10-AATATTGATAAGGAT-3') were purchased from Trilink, Inc.

Instrumentation. Dynamic light scattering (DLS) data were taken with a Malvern Zetasizer Nano Series. UV-vis absorption spectra were obtained with an Agilent 8453 spectrometer. $\quad{ }^{1} \mathrm{H}$ NMR spectra were collected with Bruker DMX500, using $\mathrm{CDCl}_{3}$. All fluorescent spectra were collected with a Jobin Yvon Horiba Fluorolog3 spectrometer. A Quantum Northwest TLC50 temperature controller was used for temperature dependent fluorescence experiments. Transmission electron microscopy (TEM) images were taken on FEI-Tecnai T12 using acceleration voltage of $120 \mathrm{kV}$. Matrix-assisted laser desorption ionization time-of-flight mass spectrometry (MALDI-TOF/TOF MS) spectra were obtained 
on a Bruker Flex Series MALDI-TOF/TOF MS. GPC measurements were carried out at $30{ }^{\circ} \mathrm{C}$ at a flow rate of $1.0 \mathrm{~mL} / \mathrm{min}$ on a Perkin-Elmer Series 10 high-performance liquid chromatography system equipped with two AM gel columns (500 ̊, $5 \mu \mathrm{m} ; 1000 \AA$, $5 \mu \mathrm{m}$ ), a Perkin-Elmer 785 UV-vis detector $(254 \mathrm{~nm})$, and a Varian star 4090 refractive index (RI) detector calibrated against poly(methyl methacrylate) (PMMA) standards in THF. Optical images of polymersomes were obtained with $488 \mathrm{~nm}$ (6-fluorescein) and $515 \mathrm{~nm}$ (ethidium bromide) excitation and an $40 \mathrm{x}$ objective lens (water immersion $40 \mathrm{x} / 1.15 \mathrm{NA}$ ) using an Olympus Fluoview FV1000 confocal laser scanning microscope equipped with an inverted IX81 microscope.

\section{Synthesis of hydroxyl-terminated 1,2-polybutadiene (PBD-OH). PBD-OH was} synthesized by the anionic polymerization. ${ }^{1}$ Typically, sec-butyllithium $(3.5 \mathrm{~mL}, 1.16 \mathrm{M}$, $4.06 \mathrm{mmol}$ ) was added into $30 \mathrm{~mL}$ anhydrous THF in a $250 \mathrm{~mL}$ dry flask under an inert atmosphere. The flask was cooled to about $-65^{\circ} \mathrm{C}$ using a dry ice/isopropanol bath. A deep yellow color was observed from the solution. BD monomer $(16 \mathrm{~mL}, 189 \mathrm{mmol})$ was added via cannula to the reaction flask. The solution was slightly warmed up to $-60{ }^{\circ} \mathrm{C}$ where the solution color became yellowish orange. The reaction was kept stirring at $-60{ }^{\circ} \mathrm{C}$ for about $5 \mathrm{~h}$. EO was then added to the solution using cannula $(2 \mathrm{~mL})$. Upon the addition of EO, the solution became colorless within a minute. The solution was warmed up to room temperature by removing the cooling bath and stirred overnight. The reaction was then quenched by adding acidic methanol $(200 \mathrm{~mL})$. The solution was stirred overnight, filtered through filter paper, and concentrated by a rotary evaporator. The crude product of PBD-OH was dissolved in hexane and filtered through filter paper to remove residual inorganic salts prior to the second block polymerization. 

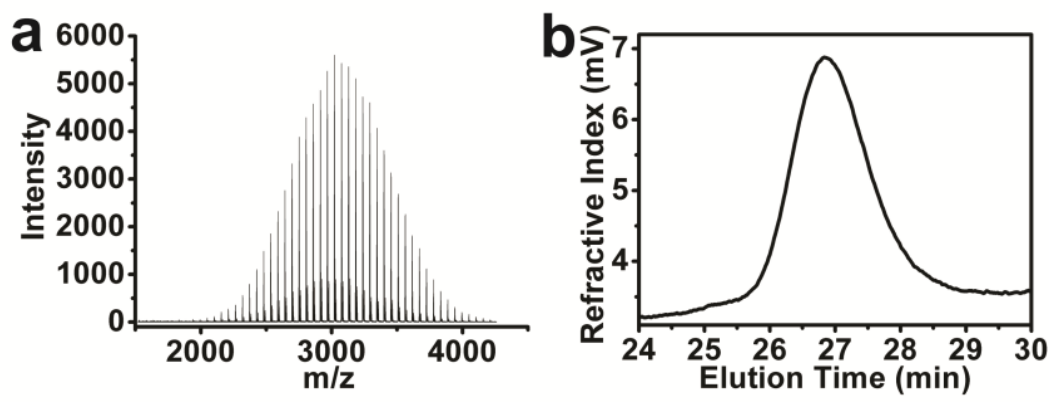

Figure S1. MALDI-TOF (a) and GPC spectra (RID trace) (b) of $\mathrm{PBD}_{52}-\mathrm{OH}$.

Synthesis of PBD-b-PEO. Typically, synthesized PBD-OH (3.86 g, $1.23 \mathrm{mmol})$ was dissolved in $15 \mathrm{~mL}$ anhydrous THF in a $250 \mathrm{~mL}$ dry flask. The PBD-OH solution was slowly titrated with freshly prepared potassium naphthalenide solution at room temperature until a light green-brown color appeared and the solution became cloudy. EO (2.2 mL, 44 mmol) was added to the solution via cannula. The green-brown color disappeared within a minute. The reaction mixture was warmed up to $40-45{ }^{\circ} \mathrm{C}$ and stirred for $24 \mathrm{~h}$. The reaction flask was allowed to cool down to room temperature and then acidic methanol (200 $\mathrm{mL}$ ) was added to the mixture to quench the reaction. The solution was kept stirring overnight, filtered by filter paper, and concentrated on a rotary evaporator. The crude product was redissolved in chloroform and washed several times by extraction with distilled water. The chloroform solution was dried over anhydrous $\mathrm{Na}_{2} \mathrm{SO}_{4}$ and concentrated on a rotary evaporator. The gel-like product was heated to $70{ }^{\circ} \mathrm{C}$ in a vacuum oven to remove residual solvents and naphthalene. 
Scheme S1. Synthetic scheme for PBD- $b$-PEO.
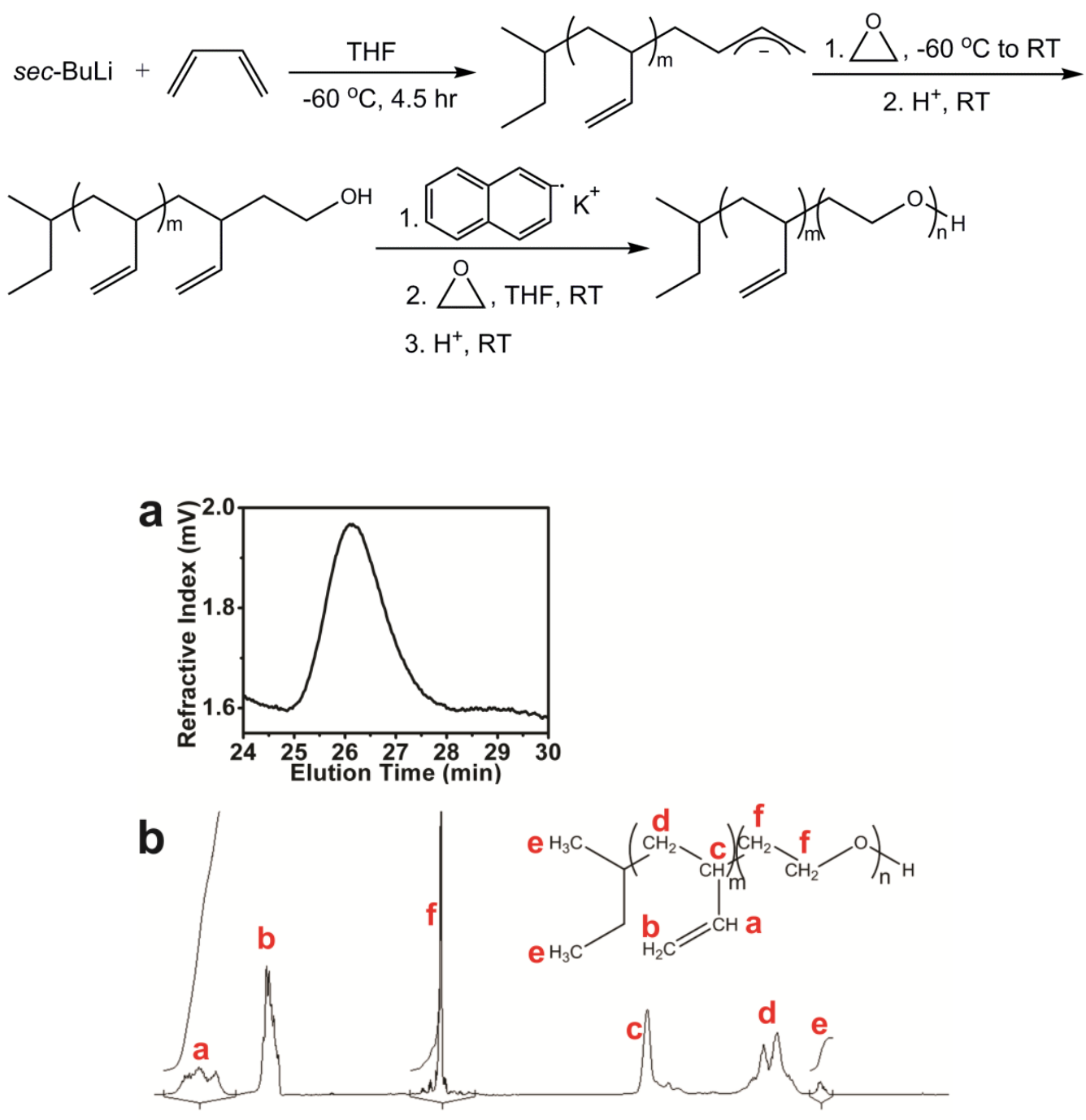

$\begin{array}{llllllllllllllll}\text { ppm } 5.2 & 4.8 & 4.4 & 4.0 & 3.6 & 3.2 & 2.8 & 2.4 & 2.0 & 1.6 & 1.2 & 0.8 & 0.4 & 0.0\end{array}$

Figure S2. GPC (RID trace) (a) and ${ }^{1} \mathrm{H}$ NMR spectra (b) of $\mathrm{PBD}_{52}-b-\mathrm{PEO}_{32}$.

Synthesis of carboxylic acid-terminated PMA (PMA-COOH). Acetone solutions of MA (2 mL, $22 \mathrm{mmol})$, RAFT-2.0 (0.1 M, $2.5 \mathrm{~mL})$ and initiator V-501 (0.02 M, $2.5 \mathrm{~mL})$, and pyrene acrylate $(0.075 \mathrm{~g})$ were mixed in a Schlenk flask. Three freeze-pump-thaw cycles were applied to the reaction flask to remove oxygen. The reaction flask was heated at $75^{\circ} \mathrm{C}$ for $6 \mathrm{~h}$ and then cooled down to room temperature. The reaction was stopped by 
introducing air to flask. The crude product was purified by precipitating in cold methanol using dry ice/acetone bath.

Scheme S2. Synthetic scheme for PMA.

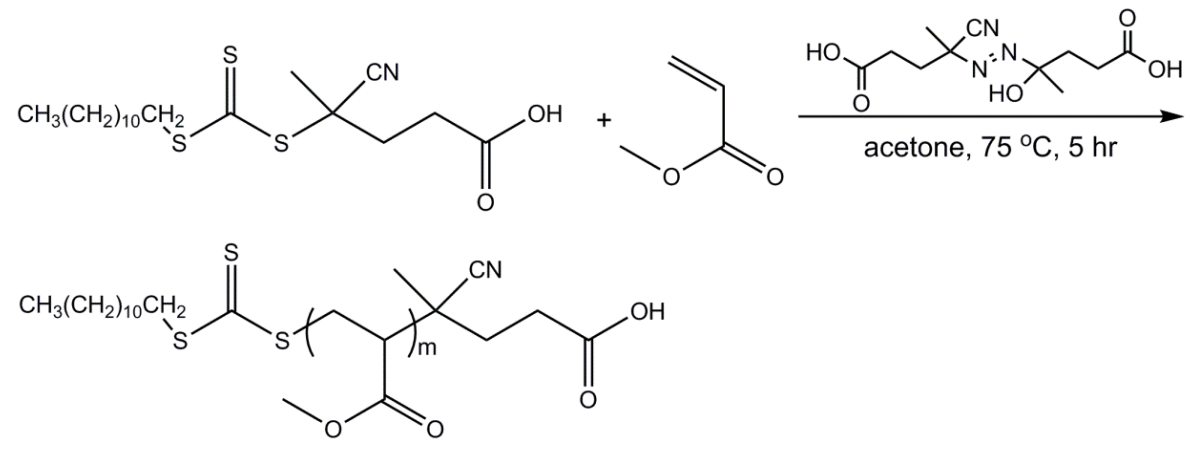
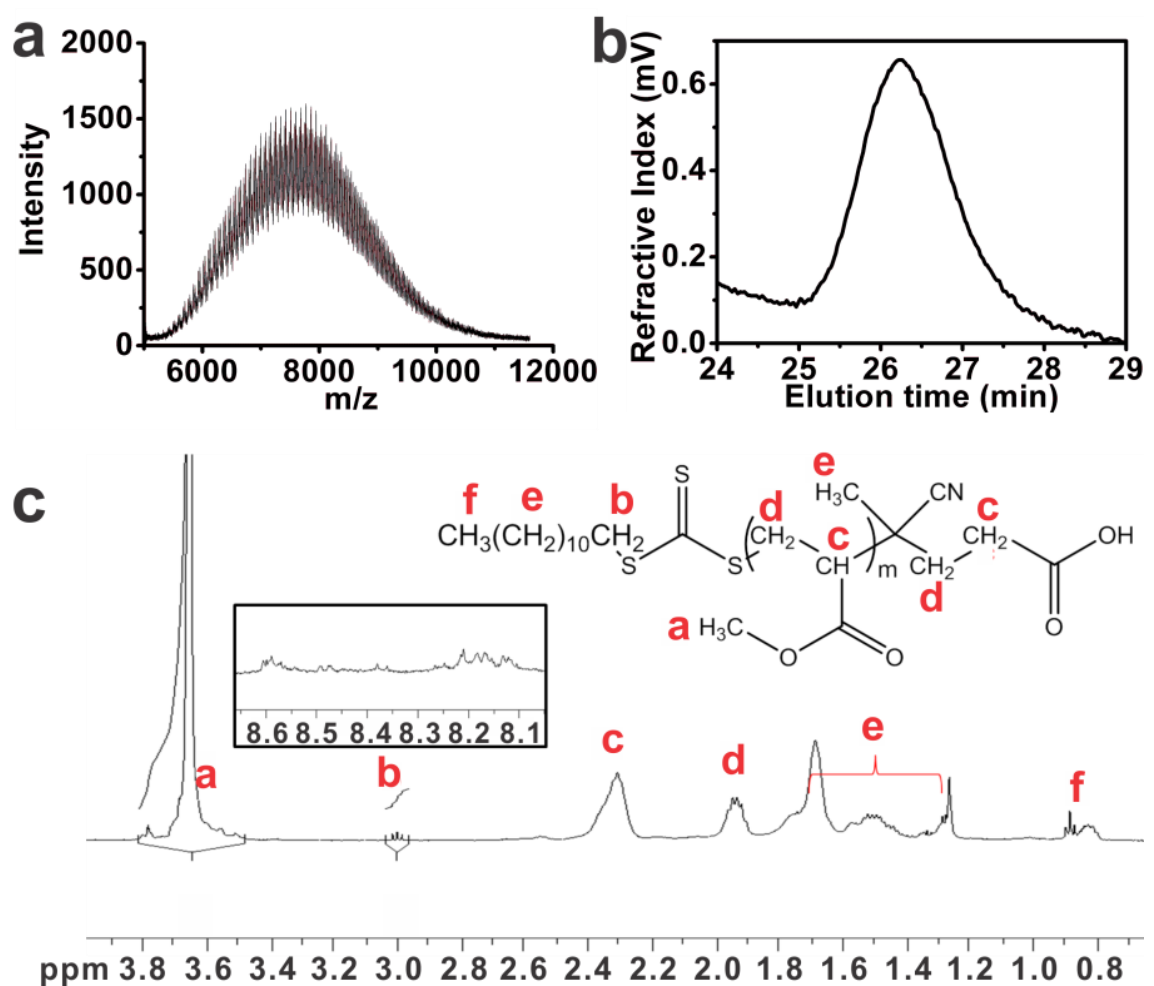

Figure S3. MALDI-TOF (a), GPC (RID trace) (b), and ${ }^{1} \mathrm{H}$ NMR spectra (c) of PMA82. 
Synthesis of PBD- $\boldsymbol{b}$-PEO- $\boldsymbol{b}$-DNA triblock copolymers. PBD- $b$-PEO- $b$-DNA was synthesized by coupling PBD- $b$-PEO and amine-terminated DNA, following a previously reported method. ${ }^{2} \quad$ Typically, $\mathrm{PBD}_{46}-b-\mathrm{PEO}_{30}(0.129 \mathrm{~g}, 34 \mu \mathrm{mol})$ was dissolved in $500 \mu \mathrm{L}$ of anhydrous DMF. $\quad N, N$-diisopropylethylamine $(48 \mu \mathrm{L}, 280 \mu \mathrm{mol})$ and HATU (13 mg, 34 $\mu \mathrm{mol})$ were added to the solution. The solution was vortexed for $10 \mathrm{~min}$ to preactivate the $\mathrm{COOH}$ group. 5'-amino-modified DNA on CPG solid support (ca. $1 \mu$ mol, MMT-deprotected) was added to the solution. The mixture was kept on a shaker at room temperature overnight. Then, the CPG beads were washed with about $200 \mathrm{~mL}$ of DMF to remove unbound PBD- $b$-PEO. Synthesized DNA block copolymers were cleaved from the beads by immersing the beads in about $1 \mathrm{~mL}$ of concentrated ammonia at $65{ }^{\circ} \mathrm{C}$. After $2 \mathrm{~h}$ reaction, ammonia was evaporated by loosening the vial cap. The CPG beads were filtered and subsequently washed with about $4 \mathrm{~mL}$ of water. DNA block copolymers and unbound single strand DNAs were collected and separated by PAGE (See below for detailed procedure for gel electrophoresis.).

Synthesis of PS- $\boldsymbol{b}$-PEO-COOH. PS- $b$-PEO-COOH was prepared by converting the hydroxyl end group of $\mathrm{PS}_{48}-b-\mathrm{PEO}_{45}-\mathrm{OH}$ to carboxylic acid, following a literature procedure. ${ }^{3}$ Sodium hydride $(15 \mathrm{mg})$ was dissolved in a mixture of THF $(2 \mathrm{~mL})$ and DMF $(1 \mathrm{~mL})$ and cooled to $0{ }^{\circ} \mathrm{C}$. $\quad$ 4-bromomethylbenzoic acid $(17 \mathrm{mg})$ dissolved in $1 \mathrm{~mL}$ of THF was added dropwise to the mixture. Subsequently, PS- $b$-PEO-OH $(0.5 \mathrm{~g})$ dissolved in THF (2 $\mathrm{mL})$ was added dropwise to the mixture. The reaction mixture was then warmed up to room temperature and stirred for 3 days. The reaction was quenched by $10 \% \mathrm{HCl}(0.5 \mathrm{~mL})$ in an ice bath and then the reacted polymer was extracted with dichloromethane $(100 \mathrm{~mL})$. The organic phase was washed with saturated $\mathrm{NaHCO}_{3}(500 \mathrm{~mL})$ and water $(500 \mathrm{~mL})$ to remove unreacted bromomethylbenzoic acid. The dichloromethane solution was dried over anhydrous $\mathrm{Na}_{2} \mathrm{SO}_{4}$ and concentrated on a rotary evaporator.

Synthesis of PS- $\boldsymbol{b}$-PEO- $\boldsymbol{b}$-DNA. $\mathrm{PS}_{48}-b-\mathrm{PEO}_{45}-\boldsymbol{b}$-DNA was synthesized by coupling $\mathrm{PS}_{48}-b-\mathrm{PEO}_{45}-\mathrm{COOH}$ and amine-terminated DNA, following a previously reported method. Typically, PS- $b$-PEO $(0.4 \mathrm{~g})$ was dissolved in $500 \mu \mathrm{L}$ of anhydrous DMF. 
$N, N$-diisopropylethylamine $(48 \mu \mathrm{L}, 280 \mu \mathrm{mol})$ and HATU (13 mg, $34 \mu \mathrm{mol})$ were added to the solution. The solution was vortexed for $10 \mathrm{~min}$ to preactivate the $\mathrm{COOH}$ group. 5'-amino-modified DNA on CPG solid support (ca. $1 \mu \mathrm{mol}$, MMT-deprotected) was added to the solution. The mixture was kept on a shaker at room temperature overnight. Then, the CPG beads were washed with about $200 \mathrm{~mL}$ of DMF to remove unbound PS- $b$-PEO. Synthesized DNA block copolymers were cleaved from the beads by immersing the beads in about $1 \mathrm{~mL}$ of concentrated ammonia at $65{ }^{\circ} \mathrm{C}$. After $2 \mathrm{~h}$ reaction, ammonia was evaporated by loosening the vial cap. The CPG beads were filtered and subsequently washed with about $4 \mathrm{~mL}$ of water. DNA block copolymers and unbound single strand DNAs were collected and separated by PAGE (See below for detailed procedure for gel electrophoresis.).
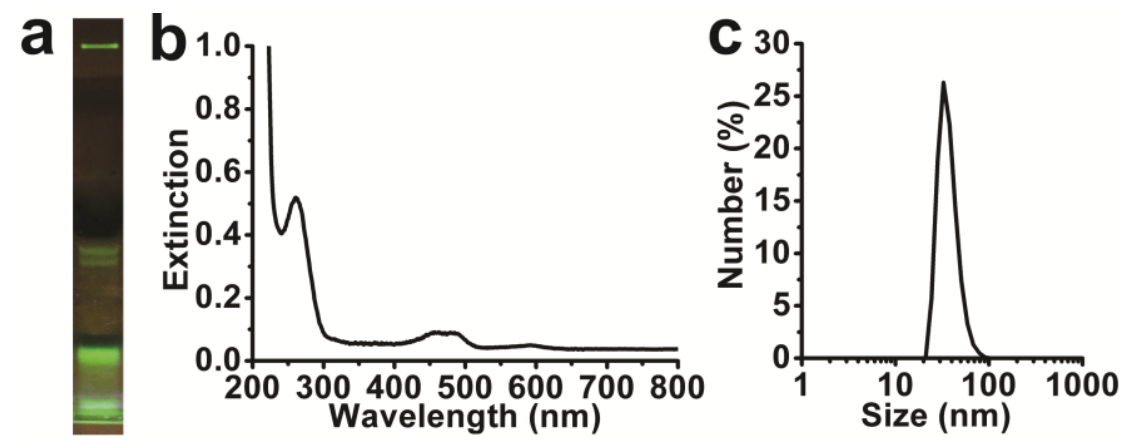

Figure S4. (a) PAGE analyses of crude product of PS- $b$-PEO- $b$-DNA. The higher band in the loading well corresponds to PS- $b$-PEO- $b$-DNA and lower bands are for unbound DNA. (b) Extinction spectrum of purified PS- $b$-PEO- $b$-DNA in water. (c) DLS data of purified PS- $b$-PEO- $b$-DNA micelles in water.

Gel electrophoresis. Gel electrophoresis was performed using Bio-Rad Criterion 15\% TBE PAGE precast gels. Crude product solutions $(1 \mathrm{~mL})$ were concentrated down to 100 $\mu \mathrm{L}$, separated into ten $10 \mu \mathrm{L}$ portions, and loaded onto each lane of the gel loading well. The gel was run in $1 \times$ Tris/boric acid/EDTA (TBE) buffer at $200 \mathrm{~V}$ for $60 \mathrm{~min}$. The lowest electrophoresis mobility band was cut with a razor blade and crushed mechanically in a 
centrifuge tube. Water $(5 \mathrm{~mL})$ was added to the tube which was then placed on a shaker overnight at room temperature to extract DNA block copolymers from gel pieces. The DNA block copolymer solution was dialyzed against water using dialysis tubing (10-12 kDa MWCO) for 2 days to remove salts.

Hybridization of DNA block copolymer micelles and gold nanoparticles. To prepare DNA-linked assemblies of DNA block copolymer micelles and gold nanoparticle aggregates, PBS solutions (100 mM NaCl, $10 \mathrm{mM}$ phosphate, $\mathrm{pH}=7.17)$ of DNA-functionalized gold nanoparticles $(3.6 \mathrm{nM}, 900 \mu \mathrm{L})$ were mixed with micelle solutions $(100 \mu \mathrm{L})$. The mixtures were kept in dry ice for $3 \mathrm{~min}$ to facilitate DNA hybridization. For thermal annealing studies, assemblies of gold nanoparticles and micelles were heated at $50{ }^{\circ} \mathrm{C}$ for $16 \mathrm{~h}$ and then cooled down to room temperature prior to measurements.

Hybridization of DNA polymersomes with plain complementary DNA. In a typical experiment, $100 \mu \mathrm{L}$ polymersome solution was combined with complementary DNA (5.86 nmol) in $0.1 \mathrm{M}$ PBS. The mixture was incubated at $55{ }^{\circ} \mathrm{C}$ for $5 \mathrm{~min}$ and then allowed to cool down to room temperature, and kept at room temperature overnight prior to the thermal denaturation curve measurements.
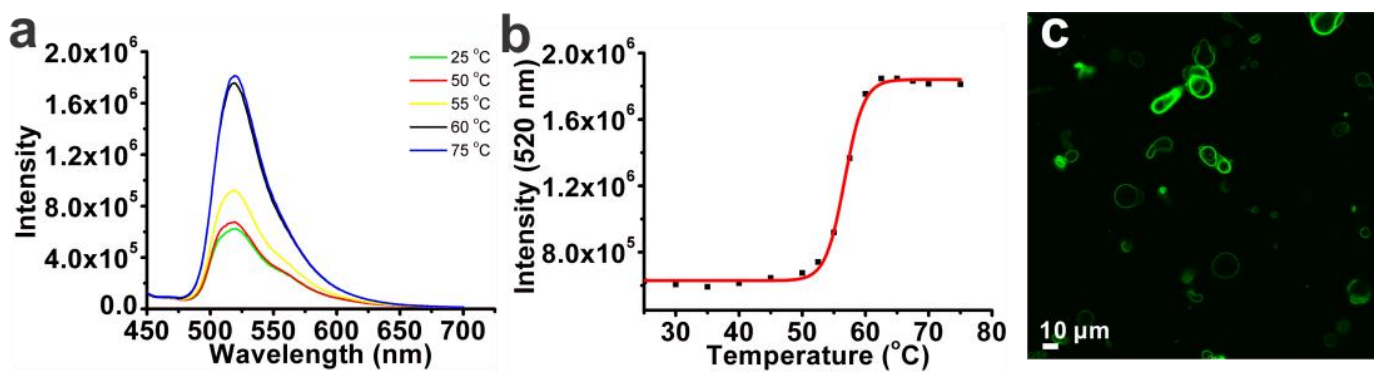

Figure S5. (a) Photoluminescence spectra of fluorescein labeled PMA- $b$-DNA polymersomes hybridized with plain complementary DNA modified with Cy3 at different temperatures.

Melting profile obtained from the temperature-dependent Föster resonance energy transfer (FRET) data in (a) by monitoring the fluorescence intensity at $520 \mathrm{~nm}$ with increasing 
temperature. (c) Confocal laser scanning fluorescence microscope image of polymersomes mixed with plain complementary DNA.

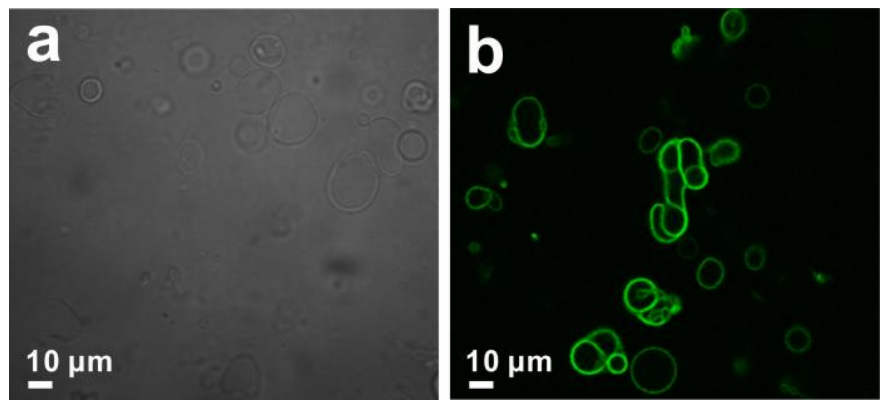

Figure S6. (a) Transmission image of polymersomes formed from PBD-b-PEO. (b) Confocal laser scanning fluorescence image of mixed polymersomes formed from PBD- $b$-PEO and PMA- $b$-DNA.
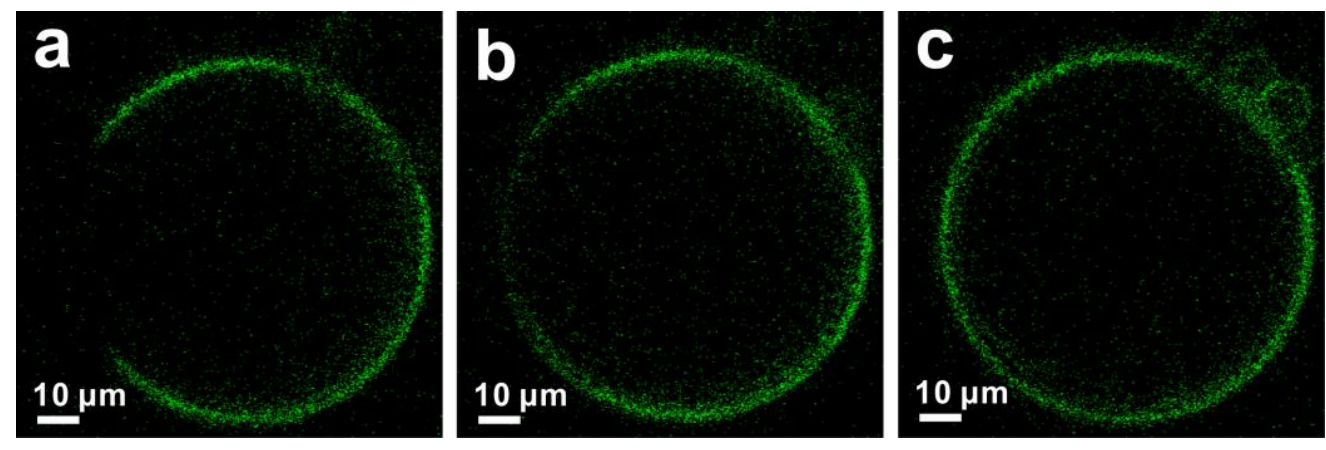

Figure S7. Fluorescence recovery after photobleaching (FRAP) experiment on a mixed polymersome formed from PBD- $b$-PEO and PMA- $b$-DNA. 6-FAM on DNA was photobleached by using a $488 \mathrm{~nm}$ laser at $100 \%$ intensity, and confocal laser scanning fluorescence images were acquired immediately after the bleaching ( $\mathrm{t}=0)(\mathrm{a})$, after a defined period of time ( $\mathrm{t}=10 \mathrm{~min})(\mathrm{b})$ and when the fluorescence intensity was fully recovered $(\mathrm{t}=20$ min) (c), respectively. 


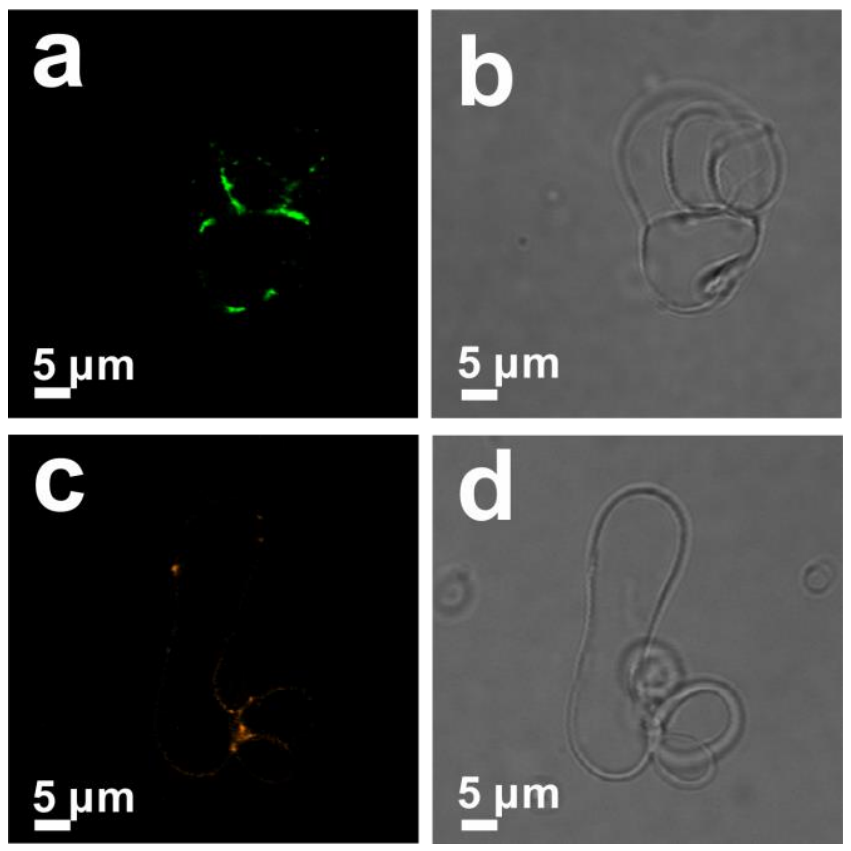

Figure S8. (a-b) Confocal laser scanning fluorescence (a) and transmission (b) images of polymersome clusters resulted from DNA hybridization. (c-d) Confocal laser scanning fluorescence (c) and transmission (d) images of polymersome clusters stained with ethidium bromide.

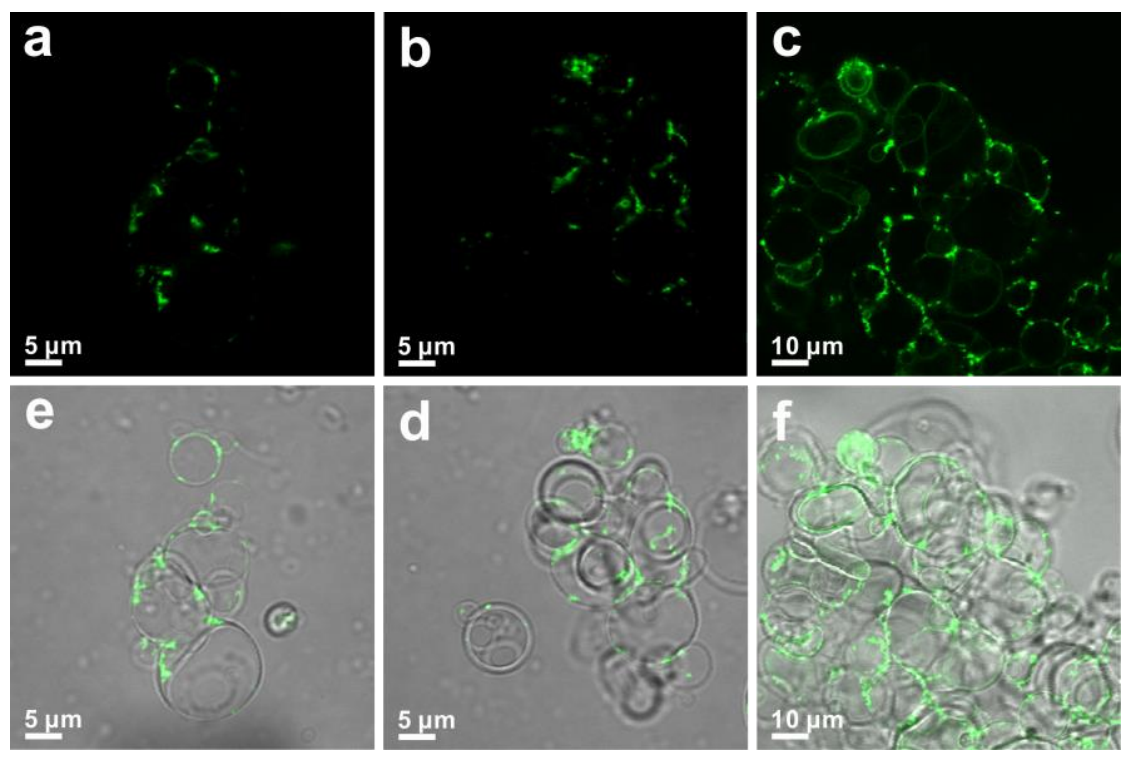

Figure S9. Additional optical microscope images of polymersome aggregates. 

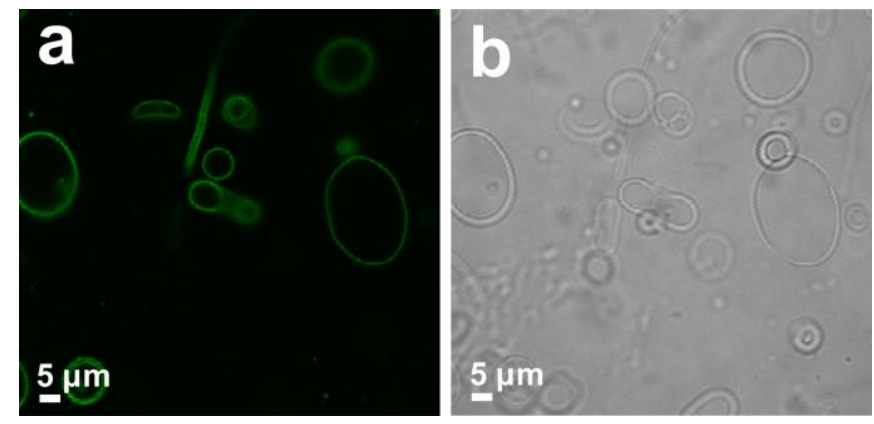

Figure S10. (a-b) Confocal laser scanning fluorescence (a) and transmission (b) images of complementary polymersomes mixed in water. No obvious polymer segregation was observed in these samples.
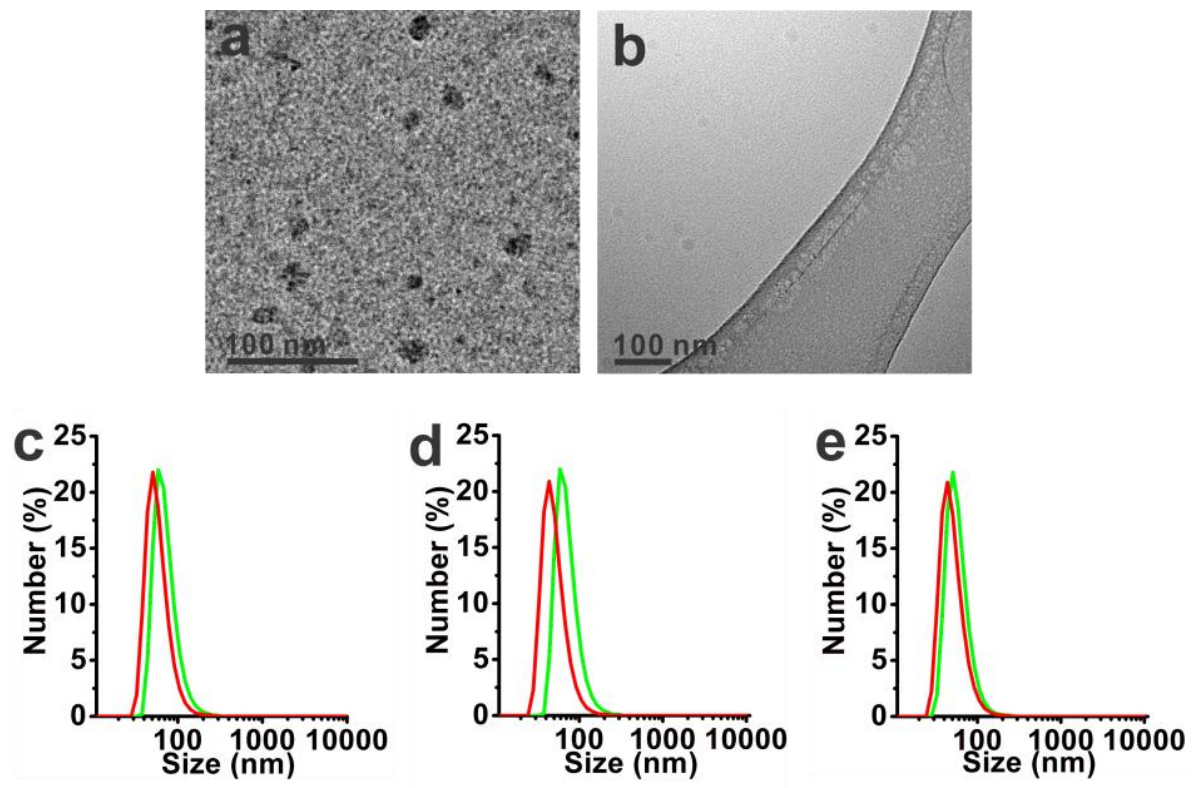

Figure S11. (a) A TEM image of assemblies composed of PBD- $b$-PEO and PBD- $b$-PEO- $b$-DNA (50 mol\% DNA block copolymer) in $0.1 \mathrm{M}$ PBS buffer (100 mM NaCl, $10 \mathrm{mM}$ phosphate buffer $\mathrm{pH}=7.17)$. (b) Cryo-TEM image of PBD- $b$-PEO and PBD- $b$-PEO- $b$-DNA mixed assemblies with 10 mol\% DNA density in 0.1 M PBS buffer. (c-e) DLS data for mixed assemblies made of PBD- $b$-PEO and PBD- $b$-PEO- $b$-DNA with 100 mol\% (c), 50 mol\% (d), and 10 mol\% (e) DNA block copolymer content. Different colors represent data collected for different batches of mixed assemblies. 

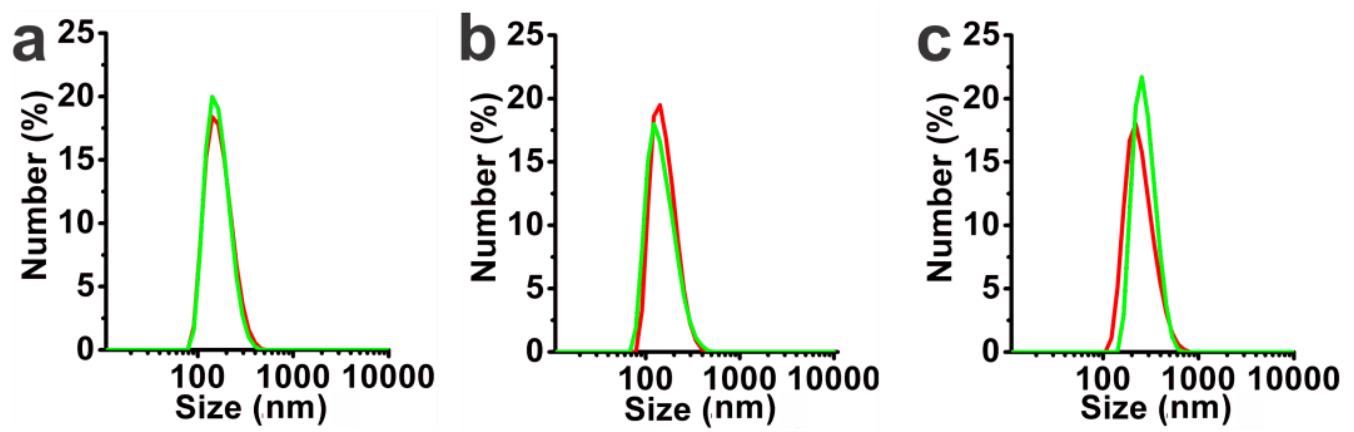

Figure S12. DLS data for mixed assemblies made of PS- $b$-PEO and PS- $b$-PEO- $b$-DNA with $100 \mathrm{~mol} \%$ (a), $50 \mathrm{~mol} \%$ (b), and $10 \mathrm{~mol} \%$ (c) DNA block copolymer content. Different colors represent data collected for different batches of mixed assemblies.
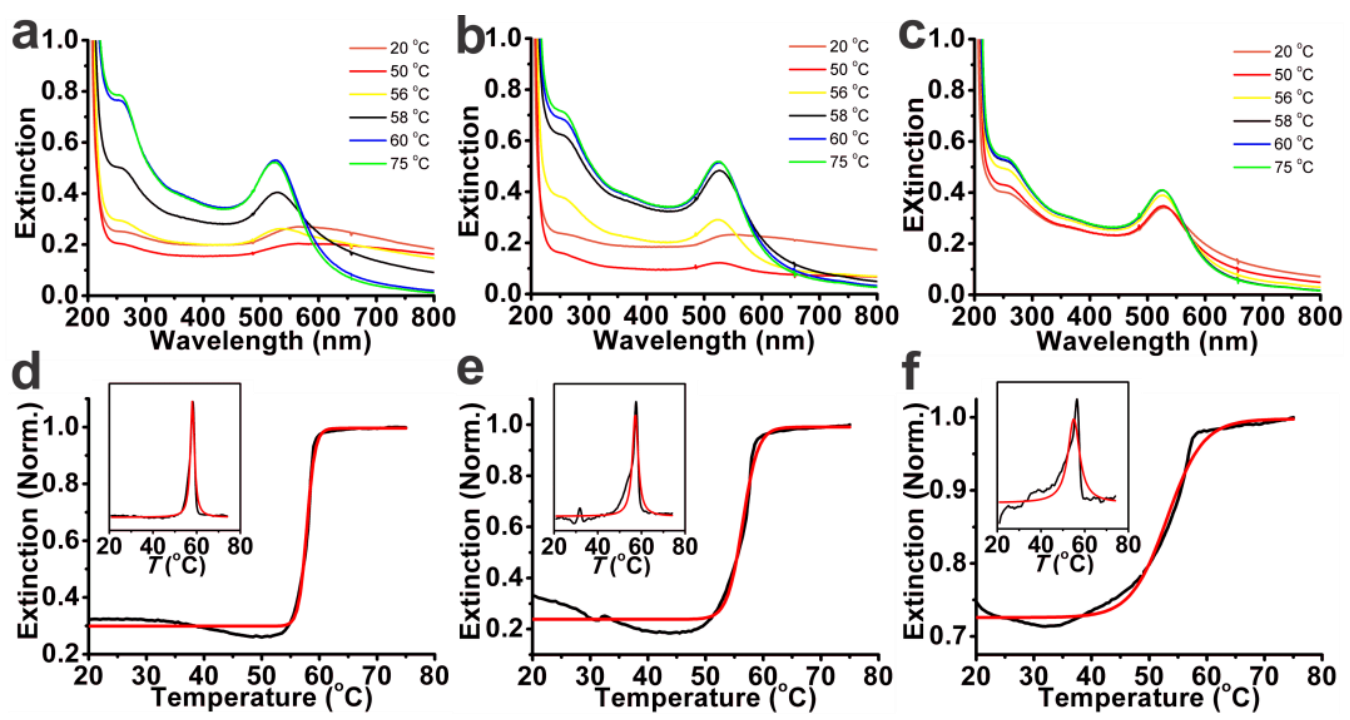

Figure S13. Melting profiles of gold nanoparticles and mixed assemblies made of PBD- $b$-PEO and PBD- $b$-PEO- $b$-DNA with 100 mol\% (a,d), 50 mol\% (b,e) and 10 mol\% (c,f) DNA block copolymer content without thermal annealing. 

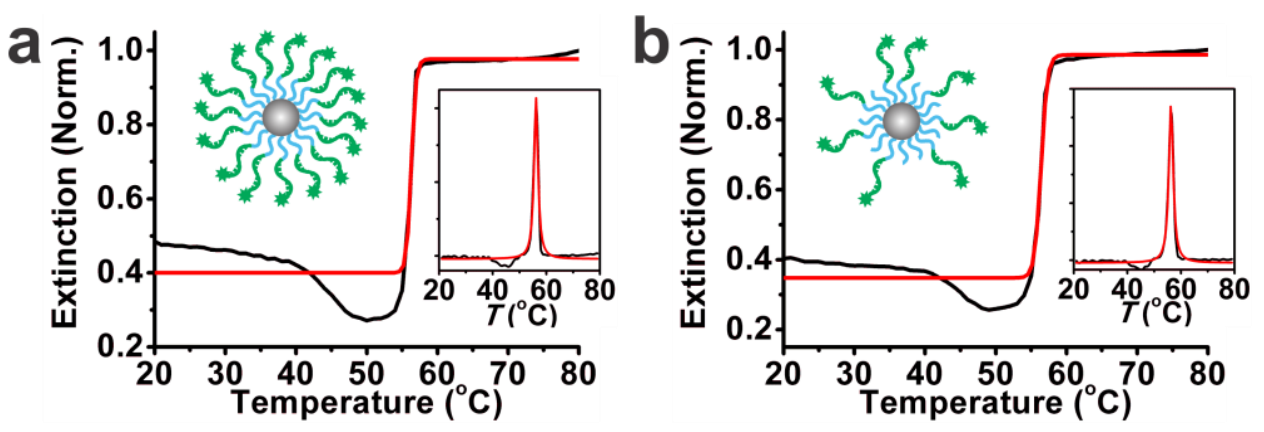

Figure S14. Melting profiles of PS- $b$-PEO and PS- $b$-PEO- $b$-DNA mixed assemblies with 100 mol\% (a) and 50 mol\% (b) DNA block copolymer content with thermal annealing.
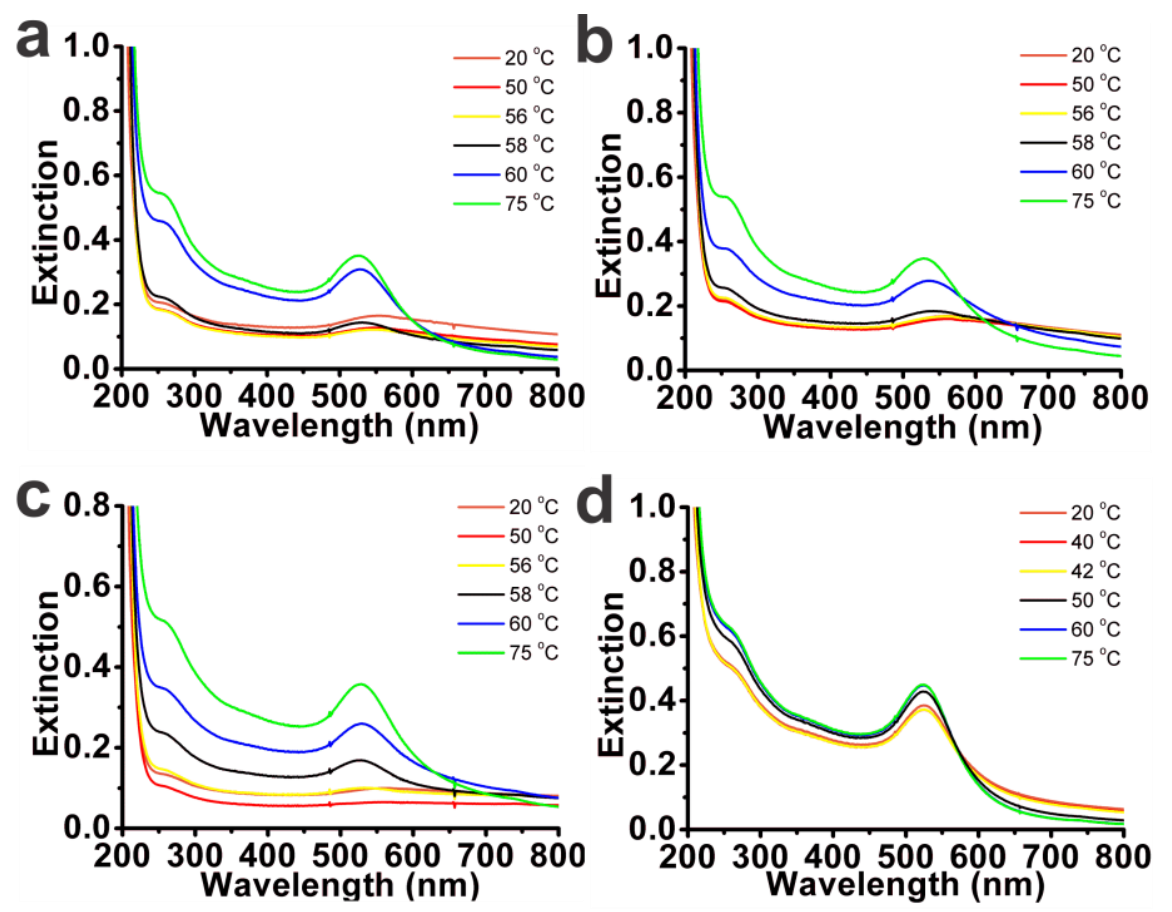

Figure S15. Temperature-dependent extinction spectra used to construct the melting curves shown in Figure 6 for mixed assemblies made of PBD- $b$-PEO and PBD- $b$-PEO- $b$-DNA with $100 \mathrm{~mol} \%$ (a), $50 \mathrm{~mol} \%$ (b) and $10 \mathrm{~mol} \%$ (c) DNA block copolymer content, and assemblies made of PS- $b$-PEO and PS- $b$-PEO- $b$-DNA with 10 mol\% DNA block copolymer content (d). 

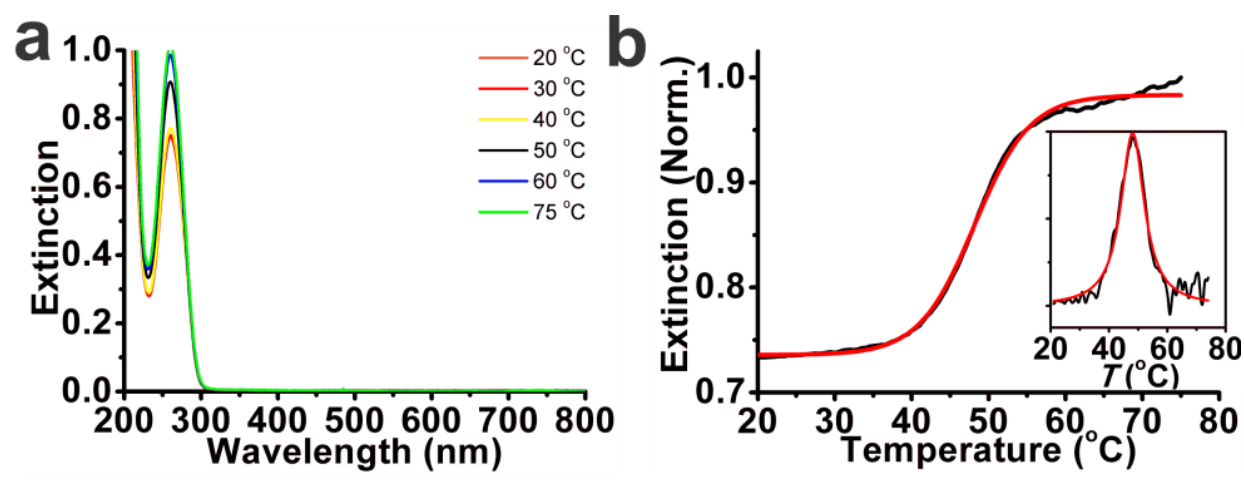

Figure S16. (a-b) Melting profile (b) of plain DNA, obtained by monitoring the absorbance at $260 \mathrm{~nm}$ with increasing temperature (a).

Table S1. Melting temperatures and FWHM values for PBD- $b$-PEO- $b$-DNA mixed assemblies with or without thermal annealing.

\begin{tabular}{lccc}
\hline & DNA BCP & Tm & FWHM $\left({ }^{\circ} \mathrm{C}\right)$ \\
& mol\% & $\left({ }^{\circ} \mathrm{C}\right)$ & \\
\hline annealing & 100 & 59.1 & 1.9 \\
& 50 & 59.1 & 2.4 \\
& 10 & 58.4 & 4.1 \\
& 100 & 58.1 & 2.2 \\
& 50 & 57.5 & 2.8 \\
& 10 & 56.6 & 6.7
\end{tabular}




\section{References}

(1) Hillmyer, M. A.; Bates, F. S. Macromolecules 1996, 29, 6994-7002.

(2) Rush, A. M.; Thompson, M. P.; Tatro, E. T.; Gianneschi, N. C. ACS Nano 2013, 7, 1379-1387.

(3) Crimmins, M. T.; Martin, T. J.; Martinot, T. A. Org. Lett. 2010, 12, 3890-3893. 